11-1-2003

\title{
Alphabet Letter Recognition And Emergent Literacy Abilities Of Rising Kindergarten Children Living In Low-Income Families
}

Stephanie Wehry

University of North Florida, swehry@unf.edu

Follow this and additional works at: http://digitalcommons.wayne.edu/jmasm

Part of the Applied Statistics Commons, Social and Behavioral Sciences Commons, and the Statistical Theory Commons

\section{Recommended Citation}

Wehry, Stephanie (2003) "Alphabet Letter Recognition And Emergent Literacy Abilities Of Rising Kindergarten Children Living In Low-Income Families," Journal of Modern Applied Statistical Methods: Vol. 2 : Iss. 2 , Article 18.

DOI: $10.22237 /$ jmasm/1067645880

Available at: http://digitalcommons.wayne.edu/jmasm/vol2/iss2/18 


\title{
Alphabet Letter Recognition And Emergent Literacy Abilities Of Rising Kindergarten Children Living In Low-Income Families
}

\author{
Stephanie Wehry \\ Florida Institute of Education \\ The University of North Florida
}

\begin{abstract}
Alphabet letter recognition item responses from 1,299 rising kindergarten children from low-income families were used to determine the dimensionality of letter recognition ability. The rising kindergarteners were enrolled in preschool classrooms implementing a research-based early literary curriculum. Item responses from the TERA-3 subtests were also analyzed. Results indicated alphabet letter recognition was unitary. The ability of boys and younger children was less than girls and older children. Child-level letter recognition was highly associated with TERA-3 measures of letter knowledge and conventions of print. Classroom-level mean letter recognition ability accounted for most of variance in classroom mean TERA-3 scores.
\end{abstract}

Key words: Early childhood literacy, alphabet letter knowledge, latent variable modeling, two-level modeling, categorical factor analysis.

Introduction

The No Child Left Behind Act has focused attention on reading instruction in kindergarten through third-grade. Programs such as the Preschool Curriculum Evaluation Research (PCER) and Early Reading First (ERF) grants expand that focus to preschool curricula that support cognitive development including emergent literacy. Literacy researchers are connecting theories about the acquisition of reading and emergent literacy skills and experiences.

The emergent literacy model embodies more than reading readiness and is used to describe the acquisition of literacy on a developmental continuum. The model provides a picture of the acquisition of literacy that occurs from early childhood rather than beginning at kindergarten and further suggests literacy skills develop concurrently and interdependently.

Whitehurst and Lonigan (1998) listed vocabulary, conventions of print, emergent writing, knowledge of graphemes, graphemephoneme correspondence, and phonological

Stephanie Wehry is the Associate Director for Research at the Florida Institute of Education, University of North Florida. Email her at swerhy@unf.edu. awareness as the skill and knowledge base of emergent literacy. They further suggested emergent literacy consists of outside-in processes that include the context in which reading and writing occurs and inside-out processes that include the knowledge and skills associated with the alphabetic principle, emergent writing, and cognitive processes. Specific examples of outsidein processes include oral language, conceptual skills, and concepts of print. The inside-out processes are letter knowledge, phonological processing skills, and syntax awareness. A study by Whitehurst et al. (1999) of 4-year-old Head Start children indicated inside-out processes were much stronger influences on first- and secondgrade reading outcomes than outside-in processes.

Historically, reading has been defined in two ways; code breaking and meaning making (Riley, 1996) or as decoding and comprehension (Gough, Juel, \& Griffin, 1992; Mason, 1980; Perfetti, 1984). Two stages of reading acquisition relative to the code breaking definition were originally proposed and those models were often refined to include three stages (Frith, 1985; Gough \& Hillinger, 1980; Gough, Juel, \& Griffith, 1992; Mason, 1980; Sulzby, 1992).

The first stage involves the association of a spoken word with some visual feature of the corresponding printed word. The second stage involves cryptanalysis of printed words or 
phonological processing involving the correspondence of graphemes and phonemes, and the third stage involves orthographic processing involving the correspondence of spelling patterns and printed words. Baker, Torgeson, and Wagner (1992) studied the role of phonological and orthographic processing and determined that orthographic skills make an independent contribution to reading achievement. Goswami (1993) saw these stages as cyclical where orthographic skills enhance phonological skills, which in turn enhance orthographic skills.

Mason (1980) suggested alphabet knowledge initiates the first level of reading acquisition by facilitating the breaking down of words into letters. Later, in a critique of five studies of children's alphabet knowledge, Ehri (1983) went further and suggested children's knowledge of the alphabet is the main skill that enables them to move from the first stage to the alphabetic or phonological stage of reading acquisition and that it is difficult to separate children's letter-sound knowledge from other emergent literacy skills. Chall (1983) summarized 17 studies of the relationship between knowledge of the alphabet and future reading achievement. Although causation was not claimed, knowledge of the letters of the alphabet was seen as an important predictor of reading achievement.

Sulzby (1983) suggested children's lettername ability is integrated into a more complex set of early literacy skills and that children attempt to use some mechanism as they learn to associate letter names with their visual forms. Children learn these skills from exposure to books, songs, blocks, and learning to write their names. Sulzby (1992) further suggested alphabet letter knowledge precedes understanding the concept of word and comprehension; however, these stages reinforce each other. Bialystok (1991) suggested that children who can identify letters in non-alphabetic order and understand that letters symbolize sounds are on their way to code breaking. Riley (1996) proposed the link between alphabet letter knowledge and concepts of print is the key to why alphabet letter knowledge is such a powerful predictor of reading achievement.

Moreover, recent studies of emergent literacy have focused on the relationships between phonological awareness and later reading. But children's letter knowledge is associated in some manner with their phonological sensitivity (Bowley, 1994; Stahl \& Murray, 1994). Stahl and Murray suggested children's letter knowledge enables them to manipulate initial sounds - a skill that leads to word recognition.

Researchers have also found measures of phonological awareness independently predicted measures of word recognition and decoding (McGuiness, McGuiness, \& Donohue, 1995), and that among preschool children from low-income families, measures of phonological sensitivity were associated with measures of letter knowledge (Lonigan, Burgess, Anthony, \& Barker, 1998). Whitehurst et al. (1999) found that reading ability in early elementary school was strongly related to measures of preschool children's skills that included items requiring them to name a pictured letter and to identify initial letters and sounds of pictured and named objects - tasks that measure grapheme-phoneme relationships. Lonigan, Burgess, and Anthony (2000), in a longitudinal study, found letter knowledge was independent of phonological sensitivity, environmental print, and decoding, and that $54 \%$ of the variation in kindergarten and first grade children's reading skills was accounted for by preschool phonological sensitivity and letter knowledge.

As Adams (1990) suggested, a child's level of phonological processing is irrelevant if the child cannot identify the letters of the alphabet. If a beginning reader cannot identify the letters then the reader cannot associate sounds with letters (Bond \& Dykstra, 1967; Chall, 1967; Mason, 1980). Moreover, orthographic competency depends on the ability to visually identify and discriminate the individual letters of the alphabet. How children acquire this ability falls in the domain of perceptual learning theory.

There are two prevalent theories (Adams, 1990; Gibson \& Levin, 1975); the template and the feature theories. In the template theory, the brain stores templates of the most typical representation of the letters and stimuli are compared to the stored templates. In the feature theory, the letters of the alphabet are considered a group of symbols that share common distinct features. The brain stores the common features of different letters and matches features of stimuli to the stored list. Both theories involve search and comparison. 
Studies of children's alphabet letter knowledge span more than four decades, involve preschool to third-grade children from low- and middle-income families, and use either all or a sample of the letters. Sulzby (1983) suggested knowledge of the alphabet measured in kindergarten, not later, is the predictor of reading achievement. However, Early Childhood Longitudinal Study-Kindergarten researchers reported $66 \%$ of children entering kindergarten for the first time recognized most of the letters of the alphabet (Zill \& West, 2001).

In recent studies of children's alphabet knowledge, Whitehurst et al. (1999) studied Head Start children and used a sample of letters embedded as items in another measure; Lonigan et al. (1998) studied preschool children from lowincome families and used all uppercase letters; Lonigan et al. (2000) studied preschool children from middle- to upper-income families and used all uppercase letters; and Roberts (2003) studied preschool children whose primary language was not English and used a sample of letters.

Studies of children from low-income families are especially important because one third of American children experience reading difficulties in school (Adams, 1990), and children from low-income families have comparatively lower levels of emergent literacy (Whitehurst \& Lonigan, 1998). Because individual differences in emergent literacy at entry into kindergarten are stable or increase over school years (Baydar, Brooks-Gunn, \& Furstenberg, 1993; Juel, 1988; Stevenson \& Newman, 1986), the impact of lower levels of emergent literacy follows preschool children through school. For these reasons, this study analyzed responses from rising kindergarten children from low-income families using all upper- and lowercase letters of the alphabet and other items measuring emergent literacy abilities.

Moreover, the children studied were nested in classrooms nested in locations. Head Start researchers (Westat, 1998) found significant variation in program quality across Head Start programs, centers, and classrooms with the largest variation occurring at the classroom level. Whitehurst et al. (1999) also found the performance of Head Start children differed across centers. Violating the assumption of independent observations across experimental units is a major concern with the use of nested data. In most cases, correlations between observations nested in groups are positive resulting in inflated Type I error rates in significance testing.

Further research is needed to estimate the magnitudes of intraclass correlations in preschool achievement data. In this study, classrooms were studied because of the large number of singleclassroom locations in the data and because Head Start researchers found most of the variance in program quality occurred at the classroom-level. A two-level model was used to estimate the size of the intraclass correlations; however, a two-level study confounds the effects classrooms and sites for sites with more than one classroom.

\section{Purposes Of This Study}

The primary purpose of this study was to analyze the alphabet letter recognition ability of rising kindergarten children from low-income families and determine if the ability was unitary or if it divided along the perceptual learning or instructional features (Adams, 1990; Gibson \& Levin, 1975). A second purpose of this study was to investigate the relationship between recognition of the letters of the alphabet and other measures of emergent literacy using methodology that developed an interval measurement scale and acknowledged the nested nature of the data. The three research questions about responses from rising kindergarten children from low-income families are

1. Is the ability to recognize upper- and lowercase letters of the alphabet unitary or multidimensional?

2. Does a latent trait model of children's responses on the three Test of Early Reading Ability (TERA-3) subtests confirm the test publisher's three-factor structure?

3. Using children's two-parameter normal ogive scores on alphabet letter recognition and TERA-3 subtests in a two-level model:

a. What is the relationship between children's alphabet letter knowledge and the TERA-3 subtest abilities?

b. Do these relationships differ by the age and/or gender of the children? 
c. What portion of the individual differences in the children's scores is accounted for the by the classrooms in which they learn?

d. Are differences in the classroom means of TERA-3 subtest scores predicted by classroom mean alphabet letter recognition scores?

\section{Methodology}

\section{Participants}

Data were collected from 1,299 4-year-old children during a one-month period from April 15, 2002 to May 17, 2002. All children were eligible to attend public school kindergarten the following year. Birth dates were available for 1,025 of the children and their ages as of September 1 of the school year ranged from 48 to 65 months with the average and median ages of 54.7 and 55 months, respectively. Gender was reported for 1001 children: $530(53 \%)$ were boys. The average (median) ages for boys and girls were 54.7 (55) and 54.6 (55) months, respectively. Ethnicity data were not collected; however, nearly all of the children were African American.

\section{Classroom Context}

The children were from low-income families; therefore, were considered at risk for academic failure. They were attending Head Start, faith-based, subsidized, and early intervention preschool programs located in six counties in southeastern United States. Most of the children attended classrooms in urban settings; however, a few classrooms were located in small towns. Children with complete scores and gender information were enrolled in 121 classrooms at 76 locations.

Fifty-five of the locations were singleclassroom sites, 16 of the locations were two- or three-classroom sites, and the remaining five locations had four or more classrooms at each site. All children in the study experienced at least one semester of an intensive early literacy curriculum. Classroom teachers explicitly taught the inside-out early literacy skills in classroom contexts that provided outside-in early literacy experiences (Whitehurst \& Lonigan, 1998). Agencies funding participation in the literacy curriculum provided materials, teaching strategies, and weekly coaching for preschool teachers as they explicitly taught children alphabet letter knowledge, phonemic awareness, and print concepts. Teachers also used dialogic reading (Valdez-Menchara, \& Whitehurst, 1992; Whitehurst, Arnold, Epstein, Angell, Smith, \& Fischel, 1994) and provided opportunities for emergent writing, reading, and comprehension. All instruction occurred in printrich environments with labeled furniture and word walls. The evaluation of the literacy curriculum used measures of alphabet letter recognition and other emergent literacy abilities in a pretest/posttest design. Data used in this study were the posttest data of that evaluation.

\section{Measurement}

Data were collected on the children's ability to recognize the 52 upper- and lowercase letters of the alphabet and from Form A of the Test of Early Reading Ability (TERA-3) (Reid, Hresko, \& Hammill, 2001a). Trained examiners collected responses from children in school settings in age appropriate one-on-one sessions. The children's responses were recorded on scannable forms.

\section{Alphabet Letter Recognition \\ Uppercase letter flashcards, arranged in a fixed non-alphabetic order, were presented one at a time to each child. The child was asked to name the letter. Following presentation of the 26 uppercase letters, lowercase letter flashcards, also arranged in a fixed non-alphabetic order, were presented one at a time.}

\section{TERA-3}

The TERA-3 is composed of three subtests measuring unique but related early literacy skills. Items within each subtest are arranged by difficulty and each subtest has a stopping mechanism. All children began testing with the first item in each subtest. According to Reid, Hresko, and Hammill (2001b), the Alphabet subtest measures graphophomenic knowledge, the Conventions subtest measures knowledge of conventions of English print, and the Meaning subtest measures ability to comprehend meaning of print. Published validity and reliability information indicates Cronbach Alpha coefficients of internal consistency for 4-year old children (5year-old children) for the Alphabet, Conventions, and Meaning subtests are $.94(.93), .88$ (.86), and $.94(.84)$, respectively. 
Data Analysis

Data were analyzed using Mplus 2.13 (Muthén \& Muthén, 2003). The flexibility of Mplus permits latent variable modeling with categorical indicators. The use of raw scores formed by summing correct item responses assumes all items are equally important in measuring the underlying construct and that intervals between scores are uniform across the ability continuum. In contrast, measurement modeling within the latent variable context permits a distinction between observed item scores and the underlying construct, and the continuous latent variables are free from measurement error.

Categorical confirmatory factor analyses (CFAs) were conducted using the item responses from the alphabet letter recognition and the three TERA-3 subtests. The analyses produced twoparameter normal ogive item response theory (IRT) models. The CFAs resulted in error free continuous latent variables; however, Mplus does not have the capability to use these results directly in multilevel models. Factor scores, which are estimated as in IRT modeling, were used as continuous variables in the two-level model. This procedure reintroduced some measurement error.

\section{Results \\ Alphabet Letter Recognition}

Distribution of Items and Summed Scores

Item responses were available from 1,299 rising kindergarten children. Correct responses were coded one and incorrect responses were coded zero. Table 1 shows alphabet letter item means and standard deviations. Additionally, three scores were formed by summing responses; one for uppercase letters, one for lowercase letters, and one for total of the upper- and lowercase scores. The means (standard deviations) for each of these summed scores were 16.41 (9.11), 13.69 (8.89), and 30.08 (17.74), respectively.

Adams (1990) suggested alphabet letter recognition instruction begins with the uppercase letters for preschool children, and the mean scores indicated rising kindergarten children recognized more uppercase than lowercase letters and more than $22 \%$ of the children recognized all uppercase letters. Calfee, Cullenbine, DePorcel, and Royston (cited in Mason, 1980) found the distribution of children's uppercase letter recognition ability was bimodal with most children either recognizing less than eight or more than 20 letters. Figure 1 shows the distribution of the children's upper- and lowercase letter recognition summed scores. Data pile up on both extremes of the distribution (ceiling and floor effects) as previously determined. The pattern at both extremes is more obvious in the distribution of lowercase letter responses.

Dimensionality of Alphabet Letter Recognition: Classical Test Theory

Traditional methods of assessing test dimensionality use factor analytic methods and coefficients of internal consistency as indicators. Cronbach's Alpha, a measure of internal consistency, for the 52 items was .98 indicating items consistently measured a unitary construct. Factor analysis of the alphabet letter recognition data produced four eigenvalues greater than 1.00; $26.49,1.97,1.11$, and 1.06 explaining 50.94, 3.79, 2.14 , and 2.04 percent of the variance in the observations, respectively. These eigenvalues suggested the presence of one central factor with possibly up to three additional minor or difficulty factors.

Dimensionality of Alphabet Letter Recognition: Item Response Theory

Latent variable modeling permits a measurement model of data that is error free, weighs the relative importance of each item, and places measurement on an interval scale. Several theoretical measurement models of alphabet letter recognition ability were evaluated using categorical CFA.

Alphabet letter recognition often begins with the uppercase letters as they are more visually distinct than the lowercase letters (Tinker, 1931). Therefore, Model I was a two-factor model with one factor representing the uppercase letters and one representing the lowercase letters. Model I was based on instructional strategy. 
Table 1. Summary Statistics and Model VII Factor Loadings for Items Measuring Recognition of the Upper- and Lowercase Letters of the Alphabet

\begin{tabular}{|c|c|c|c|c|c|c|}
\hline \multirow[b]{2}{*}{ Variable } & \multicolumn{3}{|c|}{ Uppercase letters } & \multicolumn{3}{|c|}{ Lowercase letters } \\
\hline & Mean & $\begin{array}{l}\text { Standard } \\
\text { deviation }\end{array}$ & $\begin{array}{l}\text { Factor } \\
\text { loading }\end{array}$ & Mean & $\begin{array}{c}\text { Standard } \\
\text { deviation }\end{array}$ & $\begin{array}{l}\text { Factor } \\
\text { loading }\end{array}$ \\
\hline $\mathrm{Aa}$ & .75 & .43 & .90 & .51 & .50 & .86 \\
\hline $\mathrm{Bb}$ & .81 & .39 & .82 & .43 & .50 & .84 \\
\hline $\mathrm{Cc}$ & .70 & .46 & .90 & .68 & .47 & .91 \\
\hline Dd & .65 & .48 & .89 & .32 & .47 & .77 \\
\hline $\mathrm{Ee}$ & .65 & .48 & .90 & .58 & .49 & .90 \\
\hline $\mathrm{Ff}$ & .57 & .50 & .93 & .42 & .49 & .91 \\
\hline $\mathrm{Gg}$ & .56 & .50 & .91 & .39 & .49 & .89 \\
\hline $\mathrm{Hh}$ & .61 & .50 & .88 & .43 & .50 & .86 \\
\hline Ii & .59 & .49 & .89 & .60 & .49 & .87 \\
\hline $\mathrm{Jj}$ & .59 & .49 & .89 & .56 & .50 & .89 \\
\hline $\mathrm{Kk}$ & .66 & .47 & .84 & .64 & .48 & .84 \\
\hline Ll & .59 & .49 & .90 & .31 & .46 & .79 \\
\hline $\mathrm{Mm}$ & .57 & .50 & .84 & .55 & .50 & .86 \\
\hline $\mathrm{Nn}$ & .57 & .50 & .88 & .39 & .49 & .82 \\
\hline Oo & .85 & .36 & .87 & .82 & .38 & .86 \\
\hline $\mathrm{Pp}$ & .65 & .48 & .91 & .54 & .50 & .86 \\
\hline $\mathrm{Qq}$ & .60 & .49 & .86 & .36 & .48 & .81 \\
\hline Ss & .65 & .47 & .88 & .63 & .48 & .89 \\
\hline $\mathrm{Tt}$ & .64 & .48 & .88 & .56 & .50 & .89 \\
\hline $\mathrm{Uu}$ & .52 & .50 & .89 & .43 & .50 & .85 \\
\hline $\mathrm{Vv}_{\mathrm{V}}$ & .45 & .50 & .87 & .46 & .50 & .86 \\
\hline Ww & .63 & .48 & .76 & .64 & .48 & .75 \\
\hline $\mathrm{Xx}$ & .71 & .45 & .75 & .72 & .45 & .76 \\
\hline Yy & .59 & .49 & .85 & .55 & .50 & .86 \\
\hline $\mathrm{Zz}$ & .65 & .48 & .88 & .63 & .48 & .86 \\
\hline
\end{tabular}

Perceptual learning theory suggests other models. One theory suggests children holistically perceive the letters and form templates in their memories for each letter learned. Another theory suggests children recognize letters by a set of distinctive visual features stored in their memories. The feature theory is more mentally efficient than the template theory.

Gibson and Levin (1975) reported that both children and adults sorted the uppercase letters of the alphabet by whether or not they have only straight-line features or have curved features in possible combination with straight-line segments. The secondary sort was by whether or not the letters with curved features have places of intersections such as B and $\mathrm{P}$, or look round such as $\mathrm{O}$ and $\mathrm{Q}$. The tertiary sort was by whether letters with straight-line features have diagonal segments such as $\mathrm{M}$ and $\mathrm{Z}$, or not such as $\mathrm{E}$ and $\mathrm{F}$. 
Figure 1.The distribution of simple summed upper- and lowercase alphabet letter recognition scores.

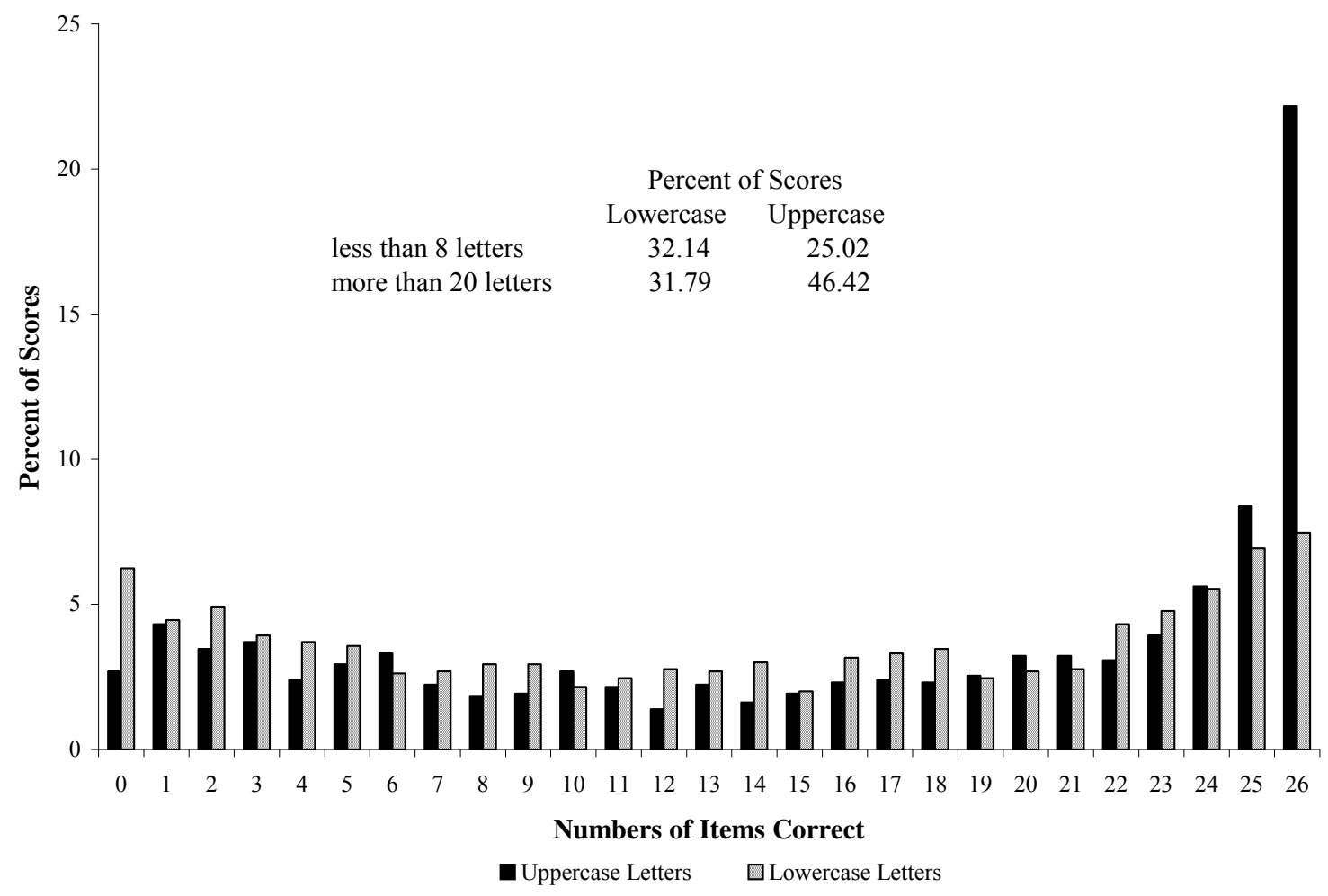

Several models involving the distinct features of the letters were investigated. Model II was a two-factor model with one factor representing letters whose visual representation is composed of diagonal line segments with no curved features (AKMNVWXYZkvwxyz) and a factor representing the remaining letters (BCDEFGHIJLOPQRSTUabcdefghijlmnopqrstu). Model III was a two-factor model with one factor representing letters whose visual representation is composed only of line segments (AEFHIKLMNTVWXYZikltvwxyz) and one representing the remaining letters (BCDGJOPQRSUabcdefghjmnopqrsu). Model IV was a two-factor model with one factor representing letters whose visual representation exhibits line symmetry (ABCDEHIMOTUVWXYZclotvwxz) and one representing the remaining letters (FGJKLNPQRSabdefghijkmnpqrsuy).
Roberts (2003) used explicit instruction to teach alphabet letter recognition to preschool children and suggested there are 44 distinct abstract symbols children must learn. She reasoned the upper- and lowercase forms for $\mathrm{C}, \mathrm{O}$, $\mathrm{S}, \mathrm{U}, \mathrm{V}, \mathrm{W}, \mathrm{X}$, and $\mathrm{Z}$ are the same. Model V was a two-factor model with one factor representing these eight pairs (COSUVWXZcosuvwxz) and one factor representing the remaining letters (ABDEFGHIJKLMNPQRTYabdefghijklmnpqrty).

Rotated exploratory factor analysis of the data suggested four highly correlated factors with one primary factor. Therefore, a unitary model, Model VI, was fit. Additionally there are at least seven letters whose upper- and lowercase visual forms are identical ( $\mathrm{C}, \mathrm{O}, \mathrm{S}, \mathrm{V}, \mathrm{W}, \mathrm{X}$, and $\mathrm{Z}$ ) and four more whose upper- and lowercase visual forms are nearly identical $(\mathrm{K}, \mathrm{P}, \mathrm{U}$, and $\mathrm{Y})$; therefore, another unitary model with errors for these eleven pairs of letters freed to correlate was also fit, Model VII. 
Categorical confirmatory factor analysis of the seven models was conducted using Mplus. A matrix of 1,299 observations, each observation having 52 binary items, was analyzed. Weighted least squares estimation (WLSM) was used to estimate model parameters. Five fit statistics are available for WLSM estimation: the comparative fit index (CFI), the Tucker-Lewis index (TLI), root mean square error approximation (RMSEA), weighted room mean square residual (WRMR), and standardized root mean square residual (SRMR). Guidelines for good fit of categorical models suggested CFI $>.95$, TLI $>.95$, RMSEA $<$ .06 , WRMR <. 90, and SRMR <. 08 ( Hu \& Bentler, 1999; Yu \& Muthén, 2002). Table 2 shows fit statistics for each of the seven models.

All seven models had CFI, TLI, and SRMR fit statistics within limits established for good fit. None of the seven models had WRMR within limits established by $\mathrm{Yu}$ and Muthén (2002). The RMSEA fit statistic of Model VII was the only one within limits and Model VII had the lowest WRMR. Therefore Model VII, a unitary model, exhibited the best overall fit and is supported by classical test theory and parsimony. Table 1 shows factor loadings for Model VII, and factor scores from Model VII were used in the two-level model.
TERA-3

TERA-3 is composed of three subtests measuring graphophemic knowledge (Alphabet), knowledge of conventions of English print (Conventions), and the ability to comprehend meaning of print (Meaning), and is designed for use with children whose ages are between three years six months and eight years six months. There are 29 Alphabet items, 21 Conventions items, and 30 Meaning items. Any subtest item whose mean was less than .05 was not used in this study. TERA-3 was administered to 1009 children in one-on-one settings by trained examiners. Correct responses were coded one and incorrect responses were coded zero. Table 3 shows TERA-3 item means and standard deviations.

\section{Subtest Alphabet}

Twenty-two Alphabet items were included in the study, and these items required children to identify pictured upper- and lowercase named letters, to name identified pictured upper- and lowercase letters, to identify initial letters and sounds of text and named words, and to choose the correct text corresponding to a pictured object. Cronbach Alpha coefficient for the Alphabet subtest items used in the study was .93.

Table 2. Fit Indices and Factor Correlations for Seven Measurement Models of Alphabet Letter Recognition.

\begin{tabular}{ccccccc}
\hline Model & CFI & TLI & RMSEA & WRMR & SRMR & Correlations \\
\hline I & $.99^{*}$ & $.99^{*}$ & .09 & 2.52 & $.05^{*}$ & .77 \\
II & $.99^{*}$ & $.99^{*}$ & .09 & 2.39 & $.05^{*}$ & .71 \\
III & $.99^{*}$ & $.99^{*}$ & .09 & 2.48 & $.05^{*}$ & .71 \\
IV & $.99^{*}$ & $.99^{*}$ & .09 & 2.51 & $.05^{*}$ & .80 \\
V & $.99^{*}$ & $.99^{*}$ & .09 & 2.34 & $.05^{*}$ & .78 \\
VI & $.99^{*}$ & $.99^{*}$ & .09 & 2.56 & $.05^{*}$ & - \\
VII & $1.00^{*}$ & $1.00^{*}$ & $.04^{*}$ & 1.31 & $.03^{*}$ & $.14-.37$ \\
\hline
\end{tabular}

Note. ${ }^{*}$ Denotes the value indicates model fit. 
Subtest Conventions

Twelve Conventions items were included in the study, and these items required children to identify pictured books that were oriented correctly for reading, to distinguish pictured text from other pictured line markings, to match pictured uppercase with corresponding lowercase letters, to distinguish between text, title, author's name, and illustrations when presented pictured first pages of a story, to identify the first and last words of a pictured paragraph, and to follow (by pointing) pictured text as it was read indicating knowledge that text is read from left to right, top to bottom, and when to turn a pictured page. Cronbach Alpha coefficient for the Conventions subtest items used in the study was .80 .

Subtest Meaning

Ten Meaning items were included in the study, and these items required children to identify pictured product labels corresponding to named product categories, to identify pictured upper- and lowercase text placed adjacent to named pictured objects, and to identify pictured text corresponding to named pictured objects when presented amongseveral sets of pictured objects with corresponding text. Cronbach Alpha coefficient for the Meaning subtest items used in the study was .74.

Confirmatory factor analysis of these 45 items was performed using Mplus. Items were restricted to measuring TERA-3 subtests suggested by test developers. However, one Conventions item, C3, involved alphabet letter knowledge; therefore, it was freed to load on both the Alphabet and Conventions latent variables. Figure 2 provides a visual representation of the model, and, as can be seen, C3 was more strongly associated with the Alphabet latent variable. Model parameters were estimated using WLSM, and fit indices were CFI $=.99$, TLI $=.99$, RMSEA $=.05$, and WRMR $=1.50$. Three of the indices, CFI, TFI, and RMSEA, indicated model fit (Yu \& Muthén, 2002). The three latent factors were correlated with the strongest correlation occurring between Alphabet and Conventions. Table 3 shows factor loadings for the TERA-3 model, and factor scores from the model were used in the two-level model.

Two-Level Path Analysis of the Alphabet Letter Recognition and TERA-3: Emergent Literacy Abilities of the Rising Kindergartners

Alphabet letter recognition Model VII factor scores (Letters) and the TERA-3 subtest factor scores (Alphabet, Conventions, and Meaning) were used in a two-level path analysis. The within-level used the child-level data and the between-level used the classroom-level data. Table 4 shows summary statistics for the 986 child-level and the 121 classroom-level factor scores of the four variables.

The analysis in multilevel terms involved the following variables and notations:

$i$ is the $i^{\text {th }}$ child of the 986 children studied,

$j$ is the $j^{\text {th }}$ classroom of the 121 classrooms studied,

Subtest $_{i j}$ is the TERA-3 subtest factor score of the $i^{\text {th }}$ child in the $j^{\text {th }}$ classroom,

Letters $_{i j}$ is the alphabet letter recognition Model VII factor score

of the $i^{\text {th }}$ child in the $j^{\text {th }}$ classroom,

Gender $_{i j}$ is the gender (girls coded 0 and boys coded 1 ) of the $i^{\text {th }}$ child in the $j^{\text {th }}$ classroom, and

$A g e_{i j}$ is the age in months on September 1 of the $i^{\text {th }}$ child in the $j^{\text {th }}$ classroom. 
All three TERA-3 subtests were simultaneously analyzed. The analysis in multilevel terms involved the following child-level and classroom-level equations:

$$
\begin{aligned}
& \text { Child-Level } \\
& \text { Subtest }_{i j}=\beta_{0 j}+\beta_{1 j}\left(\text { Letters }_{i j}\right)+\beta_{2 j}\left(\text { Gender }_{i j}\right)+\beta_{3 j}\left(\text { Age }_{i j}\right)+r_{i j} \\
& \text { Classroom-Level } \\
& \beta_{0 j}=\gamma_{00}+\gamma_{01}\left(\text { Letters }_{. j}\right)+u_{j}
\end{aligned}
$$

where,

$\beta_{0 j}$ is the mean TERA-3 subtest factor score of the $j^{\text {th }}$ classroom,

$\beta_{1 j}$ is the expected change in children's TERA-3 subtest factor scores associated

with a change in their alphabet letter recognition factor scores,

$\beta_{2 j}$ is the expected difference in boys' TERA-3 subtest factor scores,

$\beta_{3 j}$ is the expected difference in children's TERA-3 subtest factor scores associated

with a difference in their age,

$r_{i j}$ is the unaccounted for individual differences in children's TERA-3 subtest ability,

$u_{j}$ is the unaccounted for classroom differences in TERA-3 factor score classroom means,

$\gamma_{00}$ is the grand mean of the TERA-3 subtest factors scores, and

$\gamma_{01}$ is the expected change in TERA-3 subtest classroom mean factor scores associated with a change in the classroom mean alphabet letter recognition factor scores.

This set of equations was replicated for each of the three TERA-3 subtest factor scores. Figure 3 shows the child-level and classroom-level path models and results. Parameters for the multilevel path analysis were estimated using Muthén's maximum likelihood estimator for balanced data (MUMLM). The fit indices for the model were $\mathrm{CFI}=1.00, \mathrm{TFI}=.99$, $\mathrm{RMSEA}=.02$, and SRMR $<.01$ for the within model (.04 for the classroom-level model): all indicated good fit. The intraclass correlations were $.19, .21, .15$, and .17 for Letters, Alphabet, Conventions, and Meaning, respectively.
The analyses indicated that alphabet letter knowledge predicted all three TERA-3 subtest abilities. Not surprisingly, the strongest influence was on the Alphabet subtest scores. Both age and gender influenced the Alphabet subtest scores directly and indirectly through the Letters variable. Boys and younger children had lower Alphabet subtest ability than girls and older children. The child-level model accounted for almost $70 \%$ of the child-level variance in the Alphabet subtest scores.

Alphabet letter recognition ability also influenced the Conventions subtest scores with the strength of association about two thirds as large as in the Alphabet subtest scores. Following the same pattern found with the Alphabet subtest scores, age 
Table 3. Summary Statistics and CFA Factor Loadings for TERA-3 Alphabet, Conventions, and Meaning Subtests

\begin{tabular}{cccccccc}
\hline Variable & Mean & $\begin{array}{c}\text { Standard } \\
\text { deviation }\end{array}$ & $\begin{array}{c}\text { Factor } \\
\text { loading }\end{array}$ & Variable & Mean & $\begin{array}{c}\text { Standard } \\
\text { deviation }\end{array}$ & $\begin{array}{c}\text { Factor } \\
\text { loading }\end{array}$ \\
\hline A1 & .90 & .30 & .82 & M1 & .94 & .24 & .29 \\
A2 & .78 & .41 & .72 & M2 & .95 & .22 & .52 \\
A3 & .71 & .46 & .60 & M3 & .92 & .28 & .61 \\
A4 & .75 & .43 & .86 & M4 & .78 & .41 & .94 \\
A5 & .55 & .50 & .61 & M5 & .79 & .41 & .93 \\
A6 & .57 & .50 & .78 & M6 & .81 & .39 & .74 \\
A7 & .43 & .50 & .70 & M7 & .89 & .31 & .87 \\
A8 & .43 & .50 & .93 & M8 & .25 & .43 & .66 \\
A9 & .36 & .48 & .87 & M9 & .46 & .50 & .77 \\
A10 & .36 & .48 & .90 & M10 & .09 & .29 & .53 \\
A11 & .40 & .49 & .94 & C1 & .62 & .49 & .66 \\
A12 & .38 & .49 & .89 & C2 & .52 & .50 & .43 \\
A13 & .33 & .47 & .91 & C3 & .72 & .45 & .20 \\
A14 & .21 & .41 & .78 & C4 & .68 & .47 & .75 \\
A15 & .24 & .43 & .88 & C5 & .22 & .41 & .69 \\
A16 & .28 & .45 & .90 & C6 & .45 & .50 & .58 \\
A17 & .25 & .43 & .94 & C7 & .16 & .36 & .85 \\
A18 & .09 & .29 & .79 & C8 & .29 & .46 & .80 \\
A19 & .16 & .37 & .87 & C9 & .12 & .32 & .75 \\
A20 & .17 & .38 & .89 & C10 & .08 & .28 & .82 \\
A21 & .09 & .29 & .85 & C11 & .13 & .34 & .99 \\
A22 & .11 & .31 & .83 & C13 & .09 & .29 & .90 \\
C3 & .72 & .50 & .64 & & & & \\
\hline & & & & & & & \\
\hline
\end{tabular}

Note. $\mathrm{n}=1,009$ rising kindergarten children; A1-A22 are Alphabet Subtest items; C1-C11, and C13 are Conventions Subtest items; and M1-M10 are Meaning Subtest items.

and gender influenced the Conventions subtest scores both directly and indirectly through the Letters variable. Boys and younger children had lower Conventions subtest ability than girls and older children. The child-level model accounted for almost $36 \%$ of the child-level variance in the Conventions subtest scores.

Alphabet letter recognition knowledge also influenced the Meaning subtest scores with the strength of the influence more than one fourth as large as in the Alphabet subtest scores. Age influenced the Meaning subtest scores both directly and indirectly through the Letters variable; older children had higher Meaning subtest ability than younger children. Gender influenced Meaning subtest scores only indirectly through the letters variable. The child-level model accounted for almost $19 \%$ of the child-level variance in the Meaning subtest scores.

The classroom means of the Letters variable predicted the classroom means of the Alphabet, Conventions, and Meaning subtest scores. Residuals of classroom means of all three subtest scores were significantly different from zero indicating the need for the multilevel model. The proportion of variance in TERA-3 subtest classroom means accounted for by the classroom mean ability to recognize the letters of the alphabet was 88, 60, and 27 percent, respectively for the Alphabet, Conventions, and Meaning subtests. 
Figure 2.The confirmatory factor analysis measurement model of the TERA-3 subtest items. All pictured correlations were statistically significant at $\alpha=.05$. The $t$ statistics ranged from a low value of 2.81 for Conventions measured by $\mathrm{C} 3$ to a high value of 48.35 for Alphabet measured by A4. The complete set of factor loadings is presented in Table 3.

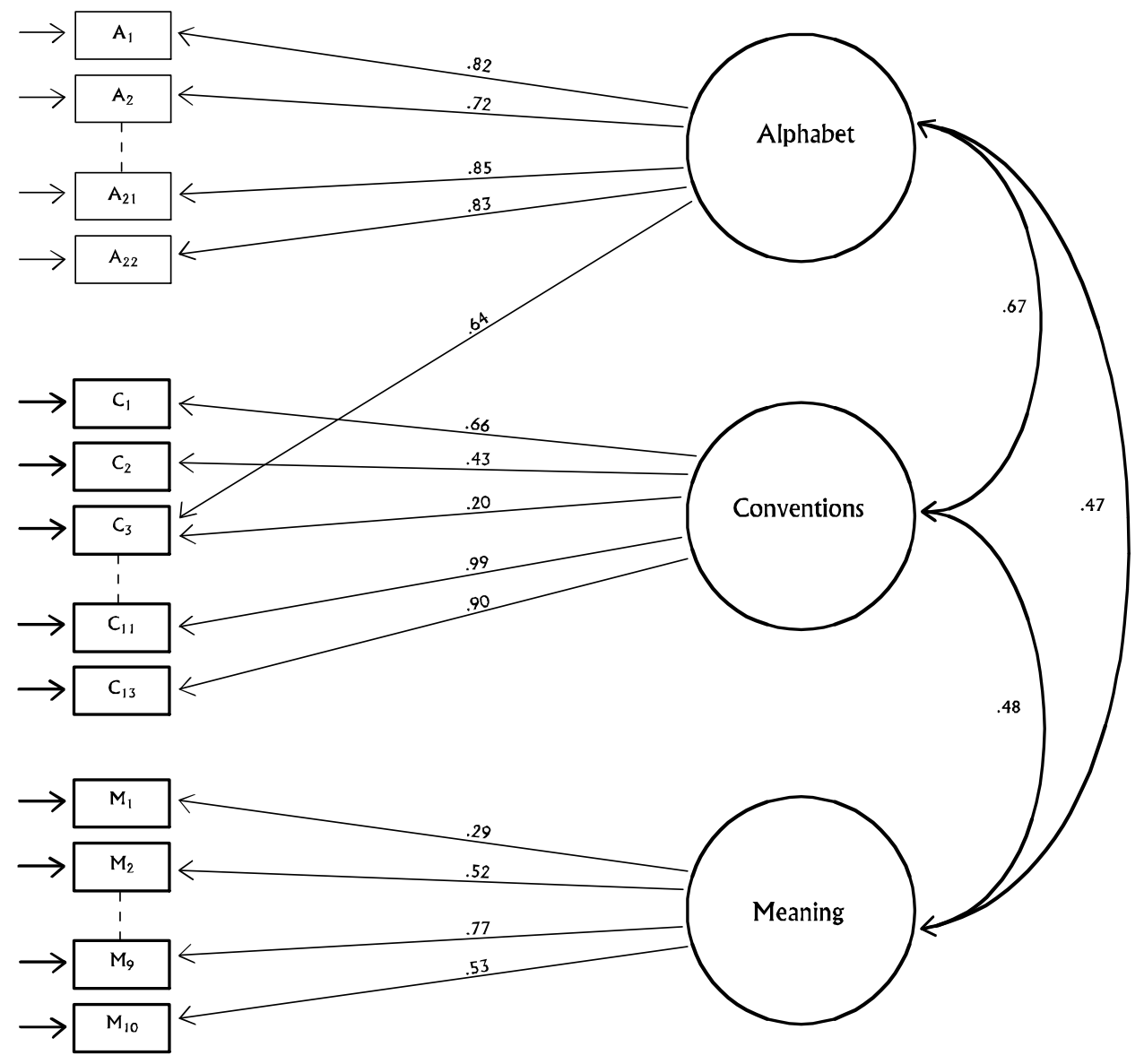


Figure 3.The two-level path analysis of the child- and classroom-level TERA-3 and alphabet letter recognition (Letters) factor scores. The pictured child-level correlations were all statistically significant at $\alpha=.05$. The child-level $t$ statistics ranged from a low of 1.98 for Alphabet by gender to a high value of 42.14 for Letters regressed on Alphabet. Additionally, the classroom-level $t$ statistics ranged from a low value of 4.67 for Mean Letters regressed on Mean Meaning to a high value of 16.51 for Mean Letters regressed on Mean Alphabet.
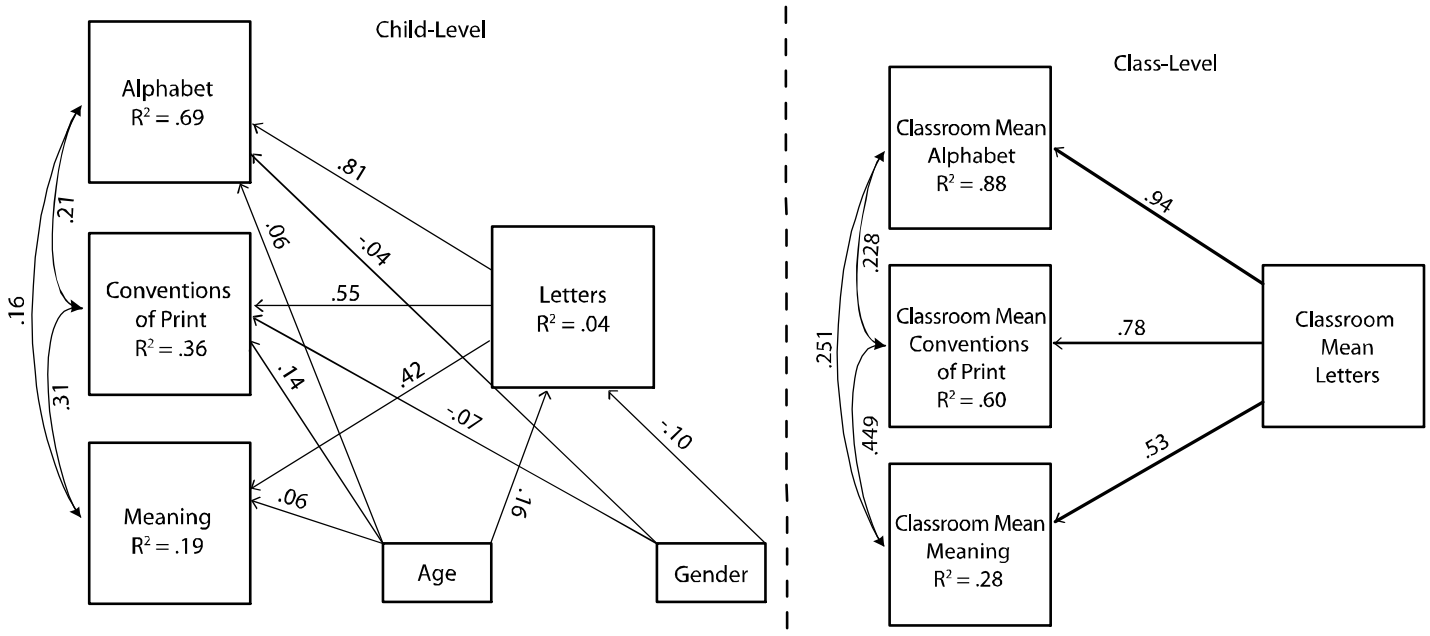

\section{Conclusion}

Participating classrooms were sponsored by agencies that were either recruited by curriculum developers for participation or whose sponsoring agencies requested participation and funded some extent of their participation. However, the participating children form a large, mostly urban, African American population of children from low-income families who attended a variety of preschool programs.

\section{Child-Level Path Analysis}

The path analyses indicated that alphabet letter knowledge predicted all three TERA-3 subtest abilities. The TERA-3 items measured alphabet letter knowledge, conventions of print, and emergent comprehension.
The findings from this study indicated the ability to recognize the upper- and lowercase letters in non-alphabetic order in classroom environments suggested by Lonigan et al. (1998) was also highly associated with measures of graphophemic knowledge, conventions of print, and knowledge of environmental print. Moreover, the classroom mean ability to recognize the letters of the alphabet accounted for differences in classroom mean measures of other emergent literacy abilities.

What is more, the link between phonological sensitivity and alphabet knowledge is especially problematic for boys from lowincome families. McGuiness et al. (1995) found that deficits in phonological awareness were more problematic to future reading achievement for boys than girls. The results of this study suggest these deficits for boys from low-income families 
may begin at the point of learning to recognize the letters of the alphabet.

The residuals of the child-level Alphabet and Conventions subtest were correlated. Both Bialystok (1991) and Sulzby (1992) suggested the influence of alphabet letter knowledge is linked to concept of word. The relationship between the alphabet letter recognition variable and the Conventions subtest scores may reflect the influence of letter recognition ability on those Conventions items requiring children to use their concept of word to respond to items that required them to follow pictured text as it was read to them or to point to various words.

\section{Classroom-Level Path Analysis}

The classroom-level model used four variables, the Letters, Alphabet, Conventions, Meaning variables aggregated at the classroom level. The classroom mean of the Letters variable predicted the classroom means of the Alphabet, Conventions, and Meaning subtest scores. The intraclass correlations for Letters, Alphabet, Conventions, and Meaning were $.19, .21, .15$, and .17 , respectively. These intraclass correlations are relatively large for a homogeneous population. For instance, in heterogeneous populations, Bryk and Raudenbush (1992) estimated $18 \%$ of the variance in math achievement scores of children in the 1982 High School and Beyond Survey was betweenschools and Goldstein (1987) estimated 9\% and $13 \%$ of the variance in reading achievement of elementary school children was between-schools and between-classes, respectively.

A possible explanation for these relatively large intraclass correlations is instruction of some of the subtest constructs is more readily adapted to the use of explicit instruction to enhance child learning. In fact, historical evaluation of the literacy curriculum used with preschool children indicated the greatest increases in mean TERA-3 subtest scores occurred with the Alphabet subtest scores. Additionally, the percent of available subtest items used in this study (items with means greater than .05) were 76, 57 and 33 percent for the Alphabet, Conventions, and Meaning subtests, respectively, and 88 and 60 percent of the classroom-level variance in the Alphabet and Conventions subtest means was accounted for by the classroom mean ability of the children to recognize the letters of the alphabet. The children in this study could correctly respond to a much greater percent of the Alphabet and Conventions than Meaning items which suggests higher ability in those areas. That ability was directly related to their classrooms' combined ability to identify the upper- and lowercase letters of the alphabet.

Because of this evidence and the explicit teaching of letter knowledge among other skills, classroom mean letter knowledge is seen as a measure of the implementation of the literacy curriculum, especially because participation was not uniformly implemented across sites in terms of the length of involvement during the school year or in terms of previous literacy curriculum experience of classroom teachers. Some teachers were new to the curriculum having worked with it less than a semester and other teachers had worked with it for several years. Supporting this implementation explanation is the fact that of the classrooms with the 16 lowest mean Letters scores, 12 were new sites with teachers new to the curriculum and with participation beginning after the winter holidays. The remaining four classrooms were early intervention special education classrooms. The implications of this explanation suggest mean classroom letter recognition ability may be simple measure of the quality of emergent literacy curricula and experiences.

Perceptual Learning Theory of Alphabet Letter Recognition

Inspection of Table 1 indicates the most frequently recognized letters were uppercase $\mathrm{A}, \mathrm{B}$, and $\mathrm{C}$ and upper- and lowercase $\mathrm{X}$ and $\mathrm{O}$. This coupled with the alphabet letter summed scores depicted in Figure 1 suggests rising kindergarten children recognized more of the uppercase letters; however, it cannot be determined from this study whether this is because the uppercase letters are more visually distinct and therefore more easily recognized (Tinker, 1931) or whether the uppercase letters are taught first to preschool children (Adams, 1990). The path analysis also indicated boys' ability to recognize letters of the alphabet was lower than girls and older children's ability was higher than younger children.

These findings are limited by the lack of experimental design, but the size of the sample indicates these are areas for further research. The fact that alphabet letter knowledge is an integral 
part of a broader set of emergent literacy skills and is frequently learned in conjunction with broader skills enhances Sulzby's (1983) call for a better understanding of how children learn letter names and the processes they use to recognize the letter forms. If children, in fact, recognize letters of the alphabet by their distinctive features, a more controlled study is needed in which data are collected earlier in the learning process and at several time points with instructional strategy modeled into the design. Perhaps as children actively engage in learning to recognize the letters of the alphabet, the construct changes from a multidimensional to a unitary one.

\section{References}

Adams, M. J. (1990). Learning about print: The first steps. In Beginning to read: Thinking and learning about print (pp. 333-367). Cambridge, MA: MIT Press.

Baker, T. A., Torgenson, J. K., \& Wagner, R. K. (1992). The role of orthographic processing skills on five different reading tasks. Reading Research Quarterly, 27, 334-345.

Baydar, N., Brooks-Gunn, J., \& Furstenberg, F. F. (1993). Early warning signs of functional illiteracy: Predictors in childhood and adolescence. Child Development, 64, 815-829.

Bialystok, E. (1991). Letters, sounds, and symbols: Changes in children's understanding of written language. Applied Psycholinguistics 12, 75-89.

Bond, G. L., \& Dykstra, R. (1967). The cooperative research program in first-grade reading instruction. Reading Research Quarterly, 2, 5-142.

Bowey, J. A. (1994). Phonological sensitivity in novice readers and nonreaders. Journal of Experimental Child Psychology, 58, 134-159.

Bryk, A. S., \& Raudenbush, S. W. (1992). Hierarchical linear models: Applications and data analyses methods. Newbury Park, CA: Sage.

Chall, J. S. (1983). The ABC's of reading: Is the alphabet necessary? In Learning to read: The great debate (pp.140-159). NY: McGraw Hill.
Ehri, L. C. (1983). A critique of five studies related to letter-name knowledge and learning to read. In L. M. Gentile, M. L. Kamil, and J. S. Blanchard (Eds.) Reading Research Revisited (143-153).Columbus, OH: Charles E. Morrill.

Frith, U. (1985). Beneath the surface of developmental dyslexia. In K. Patterson, J. Marshall, \& M. Coltheart (Eds.), Surface dyslexia (pp. 301-330). London: Erlbaum.

Gibson, E. J., \& Levin, H. (1975). A theory of perceptual learning and its relevance for understanding reading. In The psychology of reading. Cambridge, MA: MIT Press.

Goldstein, H. (1987). Multilevel models in educational and social research. New York: Oxford University Press.

Goswami, U. (1993). Orthographic analogies and reading development. Bulletin of the British Psychological Society, 6, 312-316.

Gough, P. B., \& Hillinger, M. L. (1980). Learning to read: An unnatural act. Bulletin of the Orton Society, 30, 171-176.

Gough, P. B., Juel, C., \& Griffin, P.L. (1992). Reading, spelling, and orthographic cipher. In P.B. Gough, L. C. Ehri, \& R. Treiman (Eds.), Reading acquisition (pp. 35-48). Hillsdale, NJ: Erlbaum.

Hu, L. T. \& Bentler, P. M. (1999). Cutoff criteria for fit indices in covariance structure analysis: Conventional criteria versus new alternatives. Structural Equation Modeling, 6, 155.

Juel, C. (1988). Learning to read and write: A longitudinal study of 54 children from first through fourth grades. Journal of Educational Psychology, 80, 437-447.

Lonigan, C. J., Burgess, S. R., \& Anthony, J. L. (2000). Development of emergent literacy and early reading skills in preschool children: Evidence from a latent-variable longitudinal study. Developmental Psychology, 36, 596-613.

Lonigan, C. J., Burgess, S. R., Anthony, J. L., \& Barker, T. A. (1998). Development of phonological sensitivity in 2- to 5-year-old children. Journal of Educational Psychology, 90, 294-311. 
Mason, J. M. (1980). When do children begin to read: An exploration of four-year-old children's letter and word reading competencies. Reading Research Quarterly, 13, 203-327.

McGuiness, D., McGuiness, C., \& Donohue, J. (1995). Phonological training and the alphabet principle: Evidence for reciprocal causality. Reading Research Quarterly, 30, 830852.

Muthén, B. O., \& Muthén, L. (2003). Mplus statistical analysis with latent variables Version 2.13. Los Angeles: Muthén \& Muthén.

Perfetti, C. A. (1984, November). Reading acquisition and beyond: Decoding includes cognition. American Journal of Education, 40-57.

Reid, D. K., Hresko, W. P., \& Hammill, D. D. (2000a). The Test of Early Reading Ability Third Edition. Austin, TX: Pro-Ed.

Reid, D. K., Hresko, W. P., \& Hammill, D. D. (2000b). TERA-3 examiners manual. Austin, TX: proed.

Riley, J. L. (1996). The ability to label letters of the alphabet at school entry: A discussion on its value. Journal of Research in Reading 19, 87-101.

Roberts, T. A. (2003). Effects of alphabetletter instruction on young children's word recognition. Journal of Educational Psychology, 95, 41-51.

Stahl, S. A., \& Murray, B. A. (1994). Defining phonological awareness and its relationship to early reading. Journal of Educational Psychology, 86, 221-234.

Stevenson, H. W., \& Newman, R. S. (1986). Long-term predictions of achievement and attitudes in mathematics and reading. Child Development, 57, 646-659.

Sulzby, E. (1983). A commentary on Ehri's critiques of five studies relating to lettername knowledge and learning to read: Broadening the question. In L. M. Gentile, M. L. Kamil, and J. S. Blanchard (Eds.) Reading Research Revisited (pp. 143-153). Columbus, OH: Charles E. Morrill.

Sulzby, E. (1992). Research directions: Transition from emergent to conventional writing. Language Arts, 69, 291-297.
Tinker, M. A. (1931). The influence of form of type on perception of words. Journal of Applied Psychology, 16, 167-174.

Valdez-Menchara, M. C., \& Whitehurst, G. J. (1992). Accelerating language development through picture book reading: a systematic extension to Mexican day care. Developmental Psychology, 28, 1106-1114.

Westat, Inc., Rockville, MD., Abt Associates, Inc., Bethesda, MD., CDM Group, I., \& Ellsworth Associates, Mclean, VA. (1998). Head Start Program Performance Measures. Second Progress Report. Head Start Research. U.S.; District of Columbia.

Whitehurst, G. (1999). Measurement of emergent literacy and literacy outcomes. Report to the Advisory Committee on Head Start Research and Evaluation. Retrieved January 2002 from http:〈www2.acf.dhhs.gov/programs/hsb/hsreac/jun 99/issue4.html.

Whitehurst, G. J., Arnold, D. S., Epstein, J. N., Angell, A. L., Smith, J., \& Fischel, J. E. (1994). A picture book reading intervention in day care and home for children from low-in-come families. Developmental Psychology, 30, 542-555.

Whitehurst, G. J. \& Lonigan, C. J. (1998). Child development and emergent literacy. Child Development, 68, 848-872.

Whitehurst, G. J., Zevenbergen, A. A., Crone, D. A., Schultz, M. D., Velting, O. N., \& Fischel, J. E. (1999). Outcomes of an emergent literacy intervention from Head Start through second grade. Journal of Educational Psychology, 91, 261-272.

Yu, C.-Y. \& and Muthén, B. O. (2002). Evaluation of model fit indices for latent variable models with categorical and continuous outcomes. Technical report in preparation.

Zill, N., \& West, J. (2001). Entering Kindergarten: A Portrait of American Children When They Begin School. Findings from the Condition of Education, 2000. (Rep. No. NCES2001035). U.S.; District of Columbia: ED Pubs. 